\title{
A double blind, multicentre, placebo controlled trial of lornoxicam in patients with osteoarthritis of the hip and knee
}

H Berry, H A Bird, C Black, D R Blake, A M Freeman, D N Golding, E B D Hamilton, M I V Jayson, B Kidd, H Kohn, R Million, S Ollier, I Smith, B D Williams, A D Woolf

Kings College Hospital, London,

UK

H Berry

E B D Hamilton

Royal Bath Hospital, Harrogate,

North Yorkshire,

UK

H A Bird

Royal Free Hospital,

London,

UK

C Black

The London Hospital Medical College,

London,

UK

D R Blake

B Kidd

Princess Alexandra

Hospital,

Harlow,

Essex,

UK

A $M$ Freeman

D N Golding

University of

Manchester,

Rheumatic Diseases

Centre,

Salford,

UK

M I V Jayson

R Million

14 Harley Street,

London WIN IAA

UK

H Kohn

$S$ Ollier

Coppull Medical

Practice,

Coppull,

Near Chorley,

UK

I Smith

University Hospital

of Wales,

Cardiff,

UK

B D Williams

Royal Cornwall

Hospital (City),

Truro,

Cornwall,

UK

A D Woolf

Correspondence to:

Ms Ollier.

Accepted for publication

23 April 1991

\begin{abstract}
Lornoxicam is a new non-steroidal antiinflammatory agent (NSAID) with a similar pharmacological profile to other oxicams and a potency 10 times greater than piroxicam. A multicentre, randomised, double blind, parallel group study was undertaken to compare the efficacy and tolerance of four weeks' treatment with lornoxicam ( 6 mg once daily, $4 \mathrm{mg}$ twice daily, and $6 \mathrm{mg}$ twice daily) and placebo in patients with osteoarthritis of the hip or knee.

A dose related efficacy of lornoxicam was shown by the numbers of patients in each treatment group who withdrew from the trial owing to inadequate symptom relief $(12 / 40$ (30\%) receiving placebo, $6 / 40$ (15) receiving lornoxicam $6 \mathrm{mg}$ daily, $4 / 40(10 \%)$ receiving lornoxicam $8 \mathrm{mg}$ daily, and none receiving lornoxicam $12 \mathrm{mg}$ daily). This effect was confirmed by pain relief scores, which were significantly better than placebo during treatment with lornoxicam $8 \mathrm{mg}$ and $12 \mathrm{mg}$ daily, the effect of $12 \mathrm{mg}$ daily being significantly superior to that of $8 \mathrm{mg}$ daily. Similar results were obtained from functional status scores. Mean functional index (Lequesne) scores were significantly greater than placebo only at a daily dose of $12 \mathrm{mg}$ lornoxicam. Lornoxicam was generally well tolerated, though some gastrointestinal side effects were seen as has been reported with other NSAIDs. Laboratory investigations showed no evidence of drug toxicity.
\end{abstract}

Osteoarthritis is an extremely common condition, with up to $20 \%$ of the adult population of the United Kingdom showing radiological evidence of it. ${ }^{1}$ As there are at present no disease modifying drugs with which to treat osteoarthritis the principal objective of treatment is to relieve pain and improve function. Nonsteroidal anti-inflammatory drugs (NSAIDs) remain the best treatment. The response to any given agent and the unwanted effects encountered vary between subjects, however, and this has resulted in the development of a wide range of NSAIDs. ${ }^{2}$ The oxicams are a class of NSAIDs which have made a considerable impact since their introduction. However, some concern has been expressed about the apparently high risk of gastrointestinal side effects associated with the use of some oxicams. ${ }^{3}$ As a result research has been directed towards identifying a compound combining the potency of the oxicam class with a reduced risk of unwanted effects. One such new compound is lornoxicam (6-chloro-4 - hydroxy - 2 - methyl- $N$ - (2 - pyridyl) $-2 H$-thieno- $[2,3-e][1,2]$ thiazine-3-carboxamide 1, 1-dioxide). Although lornoxicam differs from tenoxicam only by a chlorine substituent in the 6-position, major changes in the potency, efficacy, and pharmacokinetics of the compound have been reported.

Lornoxicam is a potent inhibitor of cyclooxygenase, being about 100 times more potent than tenoxicam. ${ }^{4}$ This potent inhibition of cyclo-oxygenase translates into pharmacological efficacy. In tests of acute anti-inflammatory effects in animal models lornoxicam is about 10 times more potent than tenoxicam and piroxicam, indicating that the compound should be useful in treating acute inflammatory conditions. ${ }^{4}$ Lornoxicam also shows potent effects in animal models of analgesia, being about 12 times more potent than tenoxicam. The changes effected in the tenoxicam molecule to produce lornoxicam also change the pharmacokinetic profile of the drug profoundly. The plasma half life of lornoxicam in man is four hours, ${ }^{5}$ whereas the plasma half life of tenoxicam in man has been reported to be about 70 hours. ${ }^{6} 7$ It has been postulated that a compound which can potently inhibit cyclooxygenase in inflamed joints or tissue but allow plasma concentrations to fall to those which permit recovery of normal physiological function may produce less side effects than other members of this class of compounds. ${ }^{48}$

The current study aimed at assessing the efficacy and tolerability of increasing doses of lornoxicam compared with placebo in patients with osteoarthritis of the hip or knee.

\section{Methods}

The study was conducted in nine centres in the United Kingdom and was of a double blind, randomised, placebo controlled, parallel group design. The study was approved by the ethical committee of each institution taking part and was conducted in accordance with the provisions of the Declaration of Helsinki 1974, including the revisions of the 35th World Medical Assembly in Venice 1983. All patients gave written, informed consent to participation in the study. Patients with osteoarthritis of the hip or knee were enrolled in the study if they were between 18 and 79 years of age and symptoms had been present for at least three months before entry to the trial.

The diagnosis of osteoarthritis required the satisfaction of precise criteria of pain, limitation of movement, and radiological features. In addition to experiencing pain each day during the preceding three months, patients were 
required to score between four and 13 on a functional index scale designed to provide a composite assessment of pain and limitation of movement. ${ }^{910}$ Patients whose condition had been stabilised by physiotherapy for at least one month were acceptable for the trial provided that the physiotherapy continued unchanged throughout the trial.

After enrolment patients were assessed and randomly allocated to receive either placebo or lornoxicam treatment. All patients underwent a 48 hour to one week washout period during which no NSAID treatment was permitted. On completion of the washout period patients underwent a full series of efficacy assessments and double blind treatment was started with placebo twice daily, lornoxicam $6 \mathrm{mg}$ once daily in the morning, lornoxicam $4 \mathrm{mg}$ twice daily, or lornoxicam $6 \mathrm{mg}$ twice daily. The lornoxicam was provided as tablets of strengths $4 \mathrm{mg}$ and $6 \mathrm{mg}$. The lornoxicam and placebo were identical in appearance to preserve the double blind nature of the study. Patients were instructed to take the drugs twice daily in the morning and the evening (the group receiving $6 \mathrm{mg}$ lornoxicam once daily received placebo in the evening) and were allowed no analgesics or anti-inflammatory agents other than the trial drug throughout the study. Concomitant drugs for conditions other than osteoarthritis were permitted but wherever possible a constant dosage was maintained throughout the study. Patients were reassessed two weeks after starting treatment and again two weeks later. The total period of double blind treatment was four weeks. The following outcome measures were used, assessments being made at each of the four visits: $(a)$ pain severity self assessment (five point Likert scale) ${ }^{11} ;(b)$ pain relief self assessment (four point Likert scale); (c) functional status (ability to undertake activities (five point Likert scale)); (d) functional index (Lesquesne ${ }^{9}$ ).

At each visit any pertinent clinical features were noted and patients were asked non-leading questions as to any possible adverse events during treatment. Laboratory investigations were performed on entry to and on completion of the study. Resting heart rate and blood pressure were also recorded at each attendance. Laboratory investigations included sampling of venous blood for testing of haematological, hepatic and renal function and a midstream urine sample for measurement of $\mathrm{pH}$, protein, glucose, blood, and microscopic examination. In addition, patients were provided with coloscreen self test kits ${ }^{12}$ for the investigation of the

Table 1 Comparison of treatment groups after random allocation of patients and before intervention

\begin{tabular}{|c|c|c|c|c|}
\hline & \multirow{2}{*}{$\begin{array}{l}\text { Placebo } \\
(n=42)\end{array}$} & \multicolumn{3}{|c|}{ Lornoxicam } \\
\hline & & $\begin{array}{l}6 \mathrm{mg} / \mathrm{day} \\
(n=42)\end{array}$ & $\begin{array}{l}8 m g / d a y \\
(n=42)\end{array}$ & $\underset{(n=44)}{12 \mathrm{mg} / \mathrm{dav}}$ \\
\hline \multicolumn{5}{|l|}{ Age (years) } \\
\hline $\begin{array}{l}\text { Mean } \\
\text { (Range) }\end{array}$ & $\begin{array}{l}63 \cdot 7 \\
(41-79)\end{array}$ & $\begin{array}{l}61 \cdot 2 \\
(32-79)\end{array}$ & $\begin{array}{l}61 \cdot 8 \\
(42-77)\end{array}$ & $\begin{array}{l}61 \cdot 7 \\
(43-78)\end{array}$ \\
\hline Sex (male/female) & $\begin{array}{l}(41-79) \\
16 / 26\end{array}$ & $14 / 28$ & $16 / 26$ & $\begin{array}{l}(43-18) \\
17 / 27\end{array}$ \\
\hline \multicolumn{5}{|l|}{ Duration of arthritis (years) } \\
\hline Mean & $6 \cdot 6$ & $6 \cdot 7$ & 6.0 & $9 \cdot 1$ \\
\hline $\begin{array}{l}\text { (Range) } \\
\text { Joint assessed (hip/knee) }\end{array}$ & $(0 \cdot 5-19)$ & $(0 \cdot 5-20)$ & $(0 \cdot 5-30)$ & $(0 \cdot 5-55)$ \\
\hline Joint assessed (hip/knee) & $11 / 31$ & $9 / 33$ & $10 / 32$ & $4 / 40$ \\
\hline
\end{tabular}

"There were no significant differences between the treatment groups. presence of occult blood in stools. Tests were performed in triplicate during the first and last weeks of the study. Throughout the study compliance was assessed by means of returned unused tablet counts and by direct report.

\section{STATISTICAL METHODS}

Analyses were undertaken on an 'intent to treat' basis to overcome potential bias due to withdrawals. Safety data analyses included those patients whose efficacy data was invalid owing to protocol violations. The cautious approach of using two tailed significance tests throughout (except for analyses of variance) was followed. Tests are reported as not significant if $p>0.05$.

\section{Results}

A total of 184 patients were enrolled in the study. The patients were well matched for age, sex, race, weight, height, smoking and alcohol habits, previous drug use, history of arthritis, initial radiological findings, and initial disease status (table 1). Of these 184 patients, 170 successfully completed the run in period and entered the double blind phase of the trial. After exclusion of 10 patients owing to protocol violations, valid efficacy data existed for 160 patients (40 in each treatment group). One hundred and seventeen patients completed the full four weeks of the study ( 22 in the placebo group, 32 receiving lornoxicam $6 \mathrm{mg}$ daily, 30 receiving lornoxicam $8 \mathrm{mg}$ daily, and 33 receiving lornoxicam $12 \mathrm{mg}$ daily). Of the withdrawals which occurred after entry to the double blind phase of the study, 22 were due to poor efficacy (12 in the placebo treated group, six receiving lornoxicam $6 \mathrm{mg}$ daily, four receiving lornoxicam $8 \mathrm{mg}$ daily, and none of the group receiving lornoxicam $12 \mathrm{mg}$ daily) (fig 1 ).

\section{EFFICACY ASSESSMENTS}

Mean pain relief scores during treatment were significantly greater with both lornoxicam $8 \mathrm{mg}$ daily $(\mathbf{p}<0.002)$ and lornoxicam $12 \mathrm{mg}$ daily $(p<0.0001)$ than with placebo. The score of patients receiving lornoxicam $12 \mathrm{mg}$ daily was also significantly greater than for those receiving lornoxicam $6 \mathrm{mg}$ daily $(\mathrm{p}<0.02)(\mathrm{fig} 2)$. In

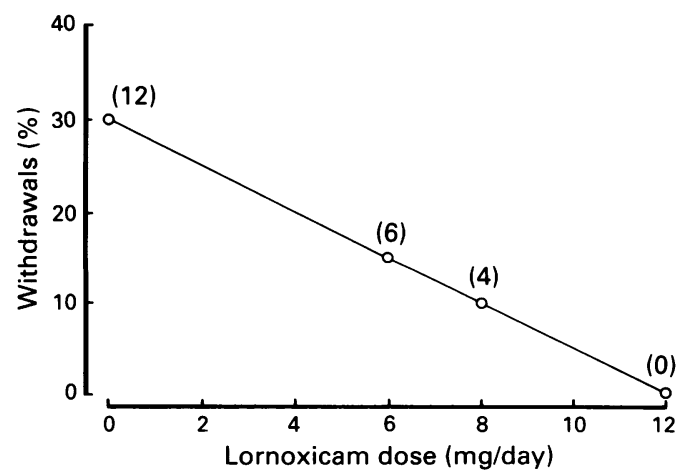

Figure 1 Percentage of patients with osteoarthritis in each treatment group withdrawn owing to lack of efficacy. Figures in parentheses indicate the number of subjects withdrawing. Each treatment group contained 40 patients. 


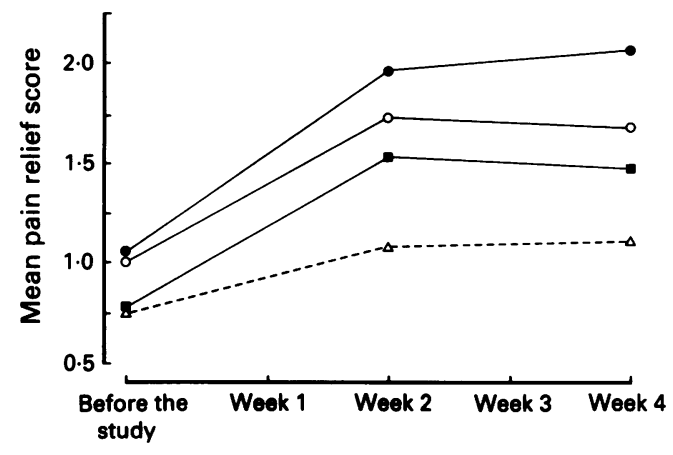

Figure 2 Mean pain relief scores after two and four weeks' treatment with lornoxicam $6 \mathrm{mg}(\mathrm{Q}), 8 \mathrm{mg}(\mathrm{O})$, and $12 \mathrm{mg}(\mathrm{O})$ daily or placebo $(\triangle)$. The effects of the two highe doses of lornoxicam, $8 \mathrm{mg}$ and $12 \mathrm{mg}$, are significantly different from that of placebo (analysis of variance; $p<0.002$ and $p<0.0001$ respectively).

addition, there were significant falls in the mean pain severity scores within all lornoxicam treated groups during the course of the study; from 2.45 to 2.08 at week 4 with $6 \mathrm{mg}$ daily $(\mathrm{p}<0.05)$, from 2.35 to 1.98 with $8 \mathrm{mg}$ daily $(\mathrm{p}<0.05)$, and from 2.33 to 1.77 with $12 \mathrm{mg}$ daily $(\mathrm{p}<0.02)$. In the placebo group there was little change; from $2 \cdot 35$ to $2 \cdot 25(\mathrm{p}=\mathrm{NS})$. The difference between treatments did not, however, reach statistical significance. Similar results were obtained from mean functional status scores which were significantly greater than placebo with both $8 \mathrm{mg}$ lornoxicam daily $(\mathrm{p}<0.05)$ and $12 \mathrm{mg}$ lornoxicam daily $(\mathrm{p}<0.0001)$. The score with lornoxicam 12 mg daily was again significantly greater than with $6 \mathrm{mg}$ daily $(\mathrm{p}<0.01)$.

The functional index (Lesquesne scores) showed little change in the placebo group from a mean score of $12 \cdot 21$ to $11.80(p=N S)$ during the study. In the groups treated with lornoxicam reductions were from 11.46 to 10.20 at week 4 with $6 \mathrm{mg}$ daily ( $\mathrm{p}<0.01$ ), from $11 \cdot 10$ to $10 \cdot 26$ with $8 \mathrm{mg}$ daily $(\mathrm{p}=\mathrm{NS})$, and from 11.54 to 9.05 with $12 \mathrm{mg}$ daily $(\mathrm{p}<0.001)$. Analysis of variance showed significant effects of treatment. Mean functional index status score was significantly greater than placebo with lornoxicam $12 \mathrm{mg}$ daily $(\mathrm{p}<0.02)$ (fig 3).

\section{SAFETY AND TOLERANCE}

There were no appreciable mean changes in

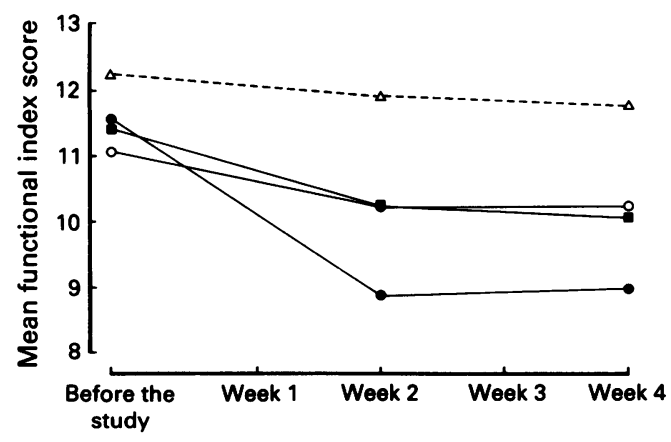

Figure 3 Mean functional index scores after two and four weeks' treatment with lornoxicam $6 \mathrm{mg}(\mathbf{0}), 8 \mathrm{mg}(\mathrm{O})$, and weeks' treatment with lormoxicam $6 \mathrm{mg}(\square), 8 \mathrm{mg}(\mathrm{O})$, and
$12 \mathrm{mg}(\mathrm{O})$ daily or placebo $(\triangle)$. The effect of lornoxicam $12 \mathrm{mg}$ daily differs significantly from that of placebo (analysis of variance; $p<0 \cdot 02$ ). heart rate or blood pressure in any of the treatment groups during the study. A small but significant mean rise of 2.03 beats per minute in heart rate occurred in the placebo group $(p<0.02)$ but was not considered to be of clinical importance. No patient developed any remarkable abnormalities in any of the laboratory variables tested during the trial. Deviations from normal were either slight or were perpetuations of abnormalities already present at trial entry. A number of laboratory variables showed statistically significant within group mean changes during the trial. In all cases, however, the mean changes were extremely small and well within the normal reference ranges. There was no consistent pattern between the various treatment groups and hence no indication that any of these mean changes were related to treatment.

There were few positive faecal occult blood test results during the study. Changes from negative results on entry to positive results on completion of the study occurred in only five patients (two receiving lornoxicam $6 \mathrm{mg}$ daily, two receiving $8 \mathrm{mg}$ daily, and one receiving $12 \mathrm{mg}$ daily). In two patients treated with lornoxicam tests changed from positive to negative during the course of treatment, while in two others pre-existing positive results remained positive during the course of the study.

Tables 2 and 3 indicate the nature and incidence of adverse events occurring during the study. Most symptoms were mild, many were non-specific, and the correlation with the trial drug was uncertain. When gastrointestinal symptoms were considered separately there were a total of six such symptoms reported in association with placebo, four with lornoxicam $6 \mathrm{mg}$ daily, five with lornoxicam $8 \mathrm{mg}$ daily, and nine with lornoxicam $12 \mathrm{mg}$ daily. There was no statistical significance in the differences between the treatment groups. Possible dyspeptic pain was reported by three patients in the placebo group, two patients receiving lornoxicam $6 \mathrm{mg}$ daily, and three patients in each of the two groups receiving higher dose lornoxicam. The incidence of reports of nausea/vomiting was similar in groups receiving placebo and active treatment, being reported by two patients receiving placebo, one patient with lornoxicam $8 \mathrm{mg}$ daily, and three patients with lornoxicam $12 \mathrm{mg}$ daily. A total of 16 patients were withdrawn from the study because of possible adverse reactions to the trial drug (five of these withdrawals occurring in the group treated with placebo). Adverse events leading to withdrawal included conjunctivitis and leg oedema (with lornoxicam $6 \mathrm{mg}$ daily), gastrointestinal problems (three patients), headache, and chest pain

Table 2 Incidence of adverse events

\begin{tabular}{lll}
\hline Treatment & $\begin{array}{l}\text { No of adverse event(s) } \\
\text { reported } \\
\text { (No of patients) }\end{array}$ & $\begin{array}{l}\text { Withdrawals owing } \\
\text { to an adverse event }\end{array}$ \\
\hline Placebo & $15(9)$ & 5 \\
Lornoxicam & & 2 \\
6 mg daily & $8(7)$ & 5 \\
12 mg daily & $19(12)$ & 4 \\
\hline
\end{tabular}


Table 3 Nature of adverse events

\begin{tabular}{|c|c|c|c|c|}
\hline & \multicolumn{4}{|c|}{ Lornoxicam } \\
\hline & $\begin{array}{l}\text { Placebo } \\
(n=42)\end{array}$ & $\begin{array}{l}6 \text { mg/day } \\
(n=42)\end{array}$ & $\begin{array}{l}8 \text { mg/day } \\
(n=42)\end{array}$ & $\begin{array}{l}12 \mathrm{mg} / \mathrm{day} \\
(\mathrm{n}=44)\end{array}$ \\
\hline $\begin{array}{l}\text { Dyspepsia, abdominal pain, indigestion, } \\
\text { bloating, flatulence, 'gurgly' stomach }\end{array}$ & 3 & 2 & 4 & 4 \\
\hline Rectal bleeding & - & - & 1 & - \\
\hline Nausea/vomiting & 2 & - & 1 & 3 \\
\hline Diarrhoea & - & 2 & - & 3 \\
\hline Constipation & 1 & - & 1 & - \\
\hline Headache/migraine & 1 & 1 & 2 & 2 \\
\hline Blurred vision & 1 & - & - & - \\
\hline Dizzy, light headed & 1 & - & - & 1 \\
\hline Lethargy/drowsy, malaise & 4 & - & 3 & 2 \\
\hline Insomnia & 1 & - & - & - \\
\hline Depression & 1 & - & - & - \\
\hline Rash & - & - & - & 1 \\
\hline Conjunctivitis, eyelid oedema & - & 1 & - & i \\
\hline Chest pain, chest tightness & - & i & 1 & 1 \\
\hline Leg oedema & - & 1 & - & - \\
\hline Palpitations & - & - & 1 & - \\
\hline Tremor & - & - & 1 & - \\
\hline Nail disorder & - & - & 1 & - \\
\hline Polyuria & - & - & i & - \\
\hline Myalgia & - & - & - & 1 \\
\hline Dry mouth & - & - & 1 & 1 \\
\hline No of patients & 9 & 7 & 12 & 17 \\
\hline
\end{tabular}

${ }^{*}$ Some patients reported more than one symptom. Run in period symptoms/events excluded.

(with lornoxicam $8 \mathrm{mg}$ daily), and gastrointestinal effects (three patients), and rash (with lornoxicam $12 \mathrm{mg}$ daily).

\section{Discussion}

Evaluation of a non-steroidal anti-inflammatory agent is always complicated by the subjective nature of the assessments, particularly in reports of pain severity, and by the high degree of placebo response which may be encountered. ${ }^{13}$ This study of large numbers of homogeneous patients confirmed the efficacy of lornoxicam in the treatment of osteoarthritis with evidence of a clear dose-response relationship. With the lowest dose studied effects were modest and not significantly superior to placebo. The highest dose studied (6 mg twice daily, $12 \mathrm{mg}$ daily), however, produced much more marked effects, which were significantly superior to placebo in relation to almost all indices of efficacy considered. In general, lornoxicam was well tolerated at all three doses during the four weeks of this study.

Lornoxicam at doses of $8 \mathrm{mg}$ and $12 \mathrm{mg}$ daily was significantly more effective than placebo in the relief of joint pain associated with osteoarthritis of the hip and knee and in relieving the limitation of activity imposed by the disease. As pain is often the limiting factor in degenerate forms of arthritis the finding that patients report significant pain relief during lornoxicam treatment is particularly important. Patients also showed improvement in fuctional index, although as this index is a composite of measures of pain, stiffness, maximum walking distance, and ease of activities of daily living, it is not possible to identify any particular aspect on which lornoxicam might be especially effective. It is not surprising that the ease of performing various tasks is enhanced by adequate pain relief irrespective of any anti-inflammatory effect of treatment. It is a well established pharmacological fact, however, that the anti-inflammatory properties of NSAIDs underlie their peripheral analgesic effects in inflamed tissue, ${ }^{14}{ }^{15}$ so that the demonstrable analgesic effect of lornoxicam may be a good indicator of its anti-inflammatory effects and therapeutic potential.

Non-steroidal anti-inflammatory drugs commonly cause indigestion, gastric erosions, or peptic ulcers and increase gastrointestinal blood loss owing to inhibition of prostaglandin synthesis. In addition to the low incidence of general adverse events encountered in this study, a relatively low proportion of gastrointestinal side effects was noted. This accords well with previous experience with lornoxicam. A recent study compared the effects of lornoxicam, indomethacin, and placebo on faecal blood loss in healthy men using a chromium-51 technique. ${ }^{16}$ In that study lornoxicam treatment was found to be associated with a lower faecal blood loss than indomethacin when given over 28 days. Blood loss was, however, slightly greater than for patients treated with placebo. Previous studies of other compounds of the oxicam class have shown tenoxicam to more than double the faecal blood loss compared with placebo, an effect similar to that of piroxicam. ${ }^{17}$ Warrington et al additionally found that upper gastrointestinal appearances at endoscopy after lornoxicam treatment were similar to those after placebo. ${ }^{16}$ Good gastric tolerance of lornoxicam is also suggested by the fact that when serum pepsinogen I was used as a marker for the integrity of the gastric mucosa no significant increase in this enzyme occurred in $94.4 \%$ of patients treated with $4 \mathrm{mg}$ twice daily for two weeks. ${ }^{18}$

In conclusion, this trial confirmed the efficacy of lornoxicam in the treatment of patients with osteoarthritis. It also showed that doses of lornoxicam up to $12 \mathrm{mg}$ daily over four weeks seem to be as well or better tolerated than would be expected for a drug of this class. We suggest that lornoxicam is likely to be a useful addition to the drugs currently available for the treatment of patients with osteoarthritis.

The authors gratefully acknowledge the clinical assistance of Brenda Bloom, Carole Perkins, Linda Jolly, Kathy Deacon, and Shelley Liu. We also acknowledge Hafslund Nycomed Pharma AG, Linz, Austria and, in particular, Dr Detlef Rosenow, vice president clinical research for their support with this project. We also thank Noeleen Gregory for help in preparing the manuscript.

1 Lawrence J S, Bremner J M, Bier F. Osteoarthrosis. Prevalence in the population and relationship between symp-
toms and x-ray changes. Ann Rheum Dis 1966; 25: 1-24.

2 Rosenbloom D, Brooks PM, Bellamy N, Buchanan WW. Clinical trials in the rheumatic diseases: a selected clinical review. New York: Praeger Scientific 1985.

3 Hershey D F, Weisman H H. Minutes of the 19th meeting of the FDA Arthritis Advisory Committee, Food and Drug Administration. Washington DC: Food and Drug Administration, 1985: 1-22.

4 Pruss T P, Stroissnig H, Radhofer-Welte S, et al. Overview of the pharmacological properties, pharmacokinetics and animal safety assessment of lornoxicam. Postgrad Med $\mathcal{F}$ 1990; 66 (suppl 4): 18-21.

5 Ankier S I, Brimelow A E, Crome P, et al. Chlortenoxicam pharmacokinetics in young and elderly volunteers. Postgrad Med F 1988; 64: 752-4

6 Albergres E, Pinquier J L, Riant P, et al. Pharmacological criteria for risk-benefit evaluation of NSAIDs. Scand Rheumatol 1988; 73 (suppl): 11.

7 Day R O, Graham G G, Williams K M. Pharmacokinetics of non-steroidal anti-inflammatory drugs. In: Brooks $P$ M ed. Clinical rheumatolog. Vol 2 . 1988: 363-93. 
8 Champion G D. Therapeutic usage of the non-steroidal antiinflammatory drugs. Med $\mathcal{F}$ Aust 1988; 149: 203.

9 Lesquesne M G, Mery C, Samson M, Gerard P. Indexes of severity of osteoarthritis of the hip and knee. Scand $\mathcal{F}$ Rheumatol 1987; 65 (suppl): 85-9.

10 Lesquesne M G, Brighton SW, Kay A, et al. European guidelines for clinical trials of new anti-rheumatic drugs. lines for clinical trials of new

11 Nunnally J C. Psychometric theory. New York: McGraw Hill, 1967: 521-3.

12 Rodney W McM, Ruggiero C. The coloscreen self-test for detection of faecal occult blood. F Fam Pract 1985; 21 : $200-4$.

13 Moertel C G, Taylor W F, Roth A, Tyce F A J. Who responds to sugar pills? Mayo Clin Proc 1976; 51: 96-100.
14 Rainsford K D. Aspirin and the salicylates. London: Butterworth, 1984

15 Rainsford K D (ed). Anti-inflammatory and anti-rheumatic drugs. Vols I-III. Boca Raton:CRC Press, 1985.

16 Warrington S J, Debbas N M G, Farthing M, et al. Lornoxicam, indomethacin and placebo: comparison of effects on faecal blood loss and upper gastrointestinal endoscopic appearance in healthy men. Postgrad Med $\mathcal{F}$ 1990; 66 : 622-6.

17 Bird H A, Hill J, Haw W M, Dixon J S, Harris P A Wright $V$. A comparison of faecal blood loss caused by tenoxicam and piroxicam in normal healthy male volunteers. Curr Med Res Opin 1985; 9: 524-8.

18 Kullich W, Klein G, Pollmann G. Influence of lornoxicam on serum pepsinogen levels. Postgrad Med F 1990; 66 (suppl 4): $46-8$. 